\title{
A rapid method to screen putative mRNA targets of any known microRNA
}

\author{
Yujing Huang, Ying Qi, Qiang Ruan*, Yanping Ma, Rong He, Yaohua Ji, Zhengrong Sun
}

\begin{abstract}
Background: microRNAs (miRNAs) are a group of regulatory RNAs that regulate gene expression by binding to specific sequences on target mRNAs. However, functional identification of mRNA targets is usually difficult and time consuming. Here we report hybrid-PCR as a new and rapid approach to screen putative mRNA targets in vitro.

Results: Fifteen putative target mRNAs for human cytomegalovirus (HCMV) miR-UL112-1, including previously confirmed HCMV IE72, were identified from mRNA-derived CDNAs using hybrid-PCR. Moreover, we randomly validated six different target candidates by luciferase reporter assays, and confirmed that their luciferase activities were down-regulated with co-transfection of HCMV miR-UL112-1.
\end{abstract}

Conclusions: Our study demonstrated that hybrid-PCR is an effective and rapid approach for screening putative miRNA targets, with much more advantage of simplicity, low cost, and ease of implementation.

\section{Background}

MicroRNAs (miRNAs) are the most studied non-coding RNAs in recent years. miRNAs are 17- to 30-nucleotide RNAs that are ubiquitously expressed in plants and animals. They regulate gene expression at the posttranscriptional level $[1,2]$ and act as key regulators in diverse regulatory pathways, including early development, cell differentiation, cell proliferation, metabolism and apoptosis [3-6]. miRNAs binding to target mRNAs often leads to blockade of translation or degradation of the target mRNAs. Identification of target mRNAs is essential for understanding the biological functions of miRNAs. miRNAs from plants induce direct cleavage and degradation by binding to the target sequences with perfect base pairing. Targets of mammalian miRNAs are often difficult to predict, because few of them match to their target mRNAs perfectly [7]. Their miRNA:mRNA duplexes often contain several mismatches, gaps and G: $\mathrm{U}$ base pairs in many positions [8]. While it is known that a so-called miRNA "seed region" (nucleotide 2-7 at the 5 '-end of miRNA) is the most important determinant for target specificity [9]. miRNA-mediated

\footnotetext{
*Correspondence: ruanq@sj-hospital.org
Virus Laboratory, the Affiliated Shengjing Hospital, China Medical University,

* Correspondence: ruanq@sj-hospital.org
Virus Laboratory, the Affiliated Shengjing Hospital, China Medical University, 110004 Shenyang, Liaoning, PR China
}

(c) 2011 Huang et al; licensee BioMed Central Ltd. This is an Open Access article distributed under the terms of the Creative Commons Attribution License (http://creativecommons.org/licenses/by/2.0), which permits unrestricted use, distribution, and reproduction in any medium, provided the original work is properly cited. pairing of seed regions to their targets $[10,11]$.

A conventional way to search for miRNA targets is by using bioinformatics. The classical model for specific miRNA target recognition by most algorithms was mainly depended on (a) the detection of seed matches and (b) thermodynamic stability of miRNA:mRNA duplexes. Different algorithms always produce divergent results $[1,12-14]$. In addition, much work has been done to develop biochemical tools to identify miRNA targets, such as HITS-CHIP [15-17] and microarray technique. Those biochemical tools have been proven to be useful in miRNA targets research, but they are not widely applied because their processes are too complicated. In this study, we reported a rapid experimental approach for screening putative target mRNAs of any known miRNA.

Polymerase Chain Reaction (PCR) is widely held as one of the most important experimental methods in molecular biology. In addition to being complementary, the stability of primer-template hybridization is essential for successful PCR reactions. These requirements are also true for miRNA target recognition. Thus we thought a pool of information of target mRNAs might be established in the manner of individually designed PCR to screen putative targets of miRNAs. Because the 
new screening approach worked mainly in the form of PCR, we named it hybrid-PCR in our study.

To investigate whether hybrid-PCR could functionally identify putative miRNA targets, human cytomegalovirus (HCMV) miR-UL112-1 was selected as the research object in our study. It was difficult to recognize target mRNAs from HCMV genome by bioinformatics, because too little information of HCMV mRNA sequences could be obtained from any database. Some functional target mRNAs of miR-UL112-1 had been identified recently, thus the efficiency of hybrid-PCR in screening putative targets could be confirmed by using those targets as references.

\section{Results}

miRNAs play the role of posttranscriptional regulation by binding to target mRNAs, hence the target sequences were screened among mRNA-derived cDNAs in hybridPCR. An oligo dT-3 sites adaptor primer was introduced into 5'-terminal of mRNA-derived cDNA during reverse transcription (Figure 1A). This primer distinguished the mRNA-derived cDNAs effectively from other DNAs or RNAs in amplification. miRNA specific hybrid-primer was designed according to the miRNA sequence. The reverse and complementary sequence of the seed region of miRNA was lacated at the 3'terminal of the hybridprimer. Hybrid-PCR was projected as semi-nested PCR using the hybrid-primer and the outer/inner primers homologous to the oligo dT-3 sites adaptor primer. Specificity of target mRNA of a given miRNA was determined by hybridization of the hybrid-primer to the sequence of mRNA-derived cDNA. A low annealing temperature of $37^{\circ} \mathrm{C}$ was applied in the first round amplification, so as to make hybrid-primer hybridize with putative target sequences in a condition similar to core body temperature. Then a second round PCR with higher annealing temperature of $55^{\circ} \mathrm{C}$ was followed for further specific amplification of sequences from putative target mRNAs. Extension was long enough to avoid incomplete amplification. The products of amplification were variable in length (Figure $2 \mathrm{~A}$ ).

To acquire the actual sequences from miR-UL112-1 putative target mRNAs, products of hybrid-PCR were purified, cloned into T-vector and sequenced. Fifty-four sequences were obtained successfully in our study. Hybrid-primer sequences and polyA structure were confirmed for a complete extremity of mRNA. mRNA specific sequences located between hybrid-primer and polyA were intercepted and used to blast online to identify their host genes. Fifty-one sequences matched sequences in GenBank and their host mRNAs were identified successfully. The other three were not identified because their specific sequences (4-6 nucleotides) were too short. Overall 15 putative target mRNAs of HCMV miR-
UL112-1 were obtained. Detailed information is reported in Table 1. HCMV immediate early protein (IE72) gene, a confirmed miR-UL112-1 target gene [18], was identified in our result (Table 1 and Figure 2B). The miR-UL112-1 binding sites of three identified putative target mRNAs were not located in 3'UTR (Table 1). An extensive set of binding sites was identified in our result, such as coding sequence. Perfect base pairing within seed region was not observed in all sequences.

To determine whether the putative binding sequences obtained by hybrid-PCR represent functional target sites for miR-UL112-1, we validated a number of mRNAs using another experimental approach. Six putative binding mRNAs were randomly chosen from our results above, including those whose target sites were not located in 3'UTR (HCMV UL17/18) or complementary perfectly to seed region (Homo sapiens interleukin 32 ). The target binding sequences along with flanking sequences were cloned downstream into a luciferase reporter construct pMIR respectively. So was the 3'UTR of HCMV IE72 mRNA, which was used as a positive control in luciferase reporter assays. The 3'UTR of HCMV IE86 mRNA does not contain the miR-UL112-1 target sequence [18]. A pMIR construct containing the 3'UTR of IE86 provided an ideal negative control in luciferase reporter assays. Compared to the pSilencer negative control group, co-transfection of HCMV miRUL112-1 with pMIR containing candidate target sequences all led to a decrease in luciferase activity (Figure 3). However, expression of miR-UL112-1 caused only a minor reduction in luciferase activity of pMIR containing the 3'UTR of IE86. These data demonstrate that the putative binding sites that have been validated in our study could indeed be recognized by HCMV miR-UL112-1.

Hybrid-PCR was designed to identify target sequences of a miRNA by nearly perfect base pairing of seed region through a low annealing temperature in the initial PCR. $37^{\circ} \mathrm{C}$ was used as the initial annealing temperature because it was close to the core body temperature, which was considered similar to the physiological hybridization environment. To determine whether different initial annealing temperature could affect the results of hybrid-PCR, a series of amplifications with different initial annealing temperatures $\left(37^{\circ} \mathrm{C}, 42^{\circ} \mathrm{C}\right.$ and $55^{\circ}$ $\mathrm{C})$ was processed. Then, gene specific primers were used to identify the seven validated target sequences (including IE72) among those products. As shown in Figure 4, the number of target sequences identified was decreased along with the increase of initial annealing temperature, while there was no correlativity observed between the target sequences identified by PCR with different initial annealing temperatures and the down regulation abilities of luciferase activities. 

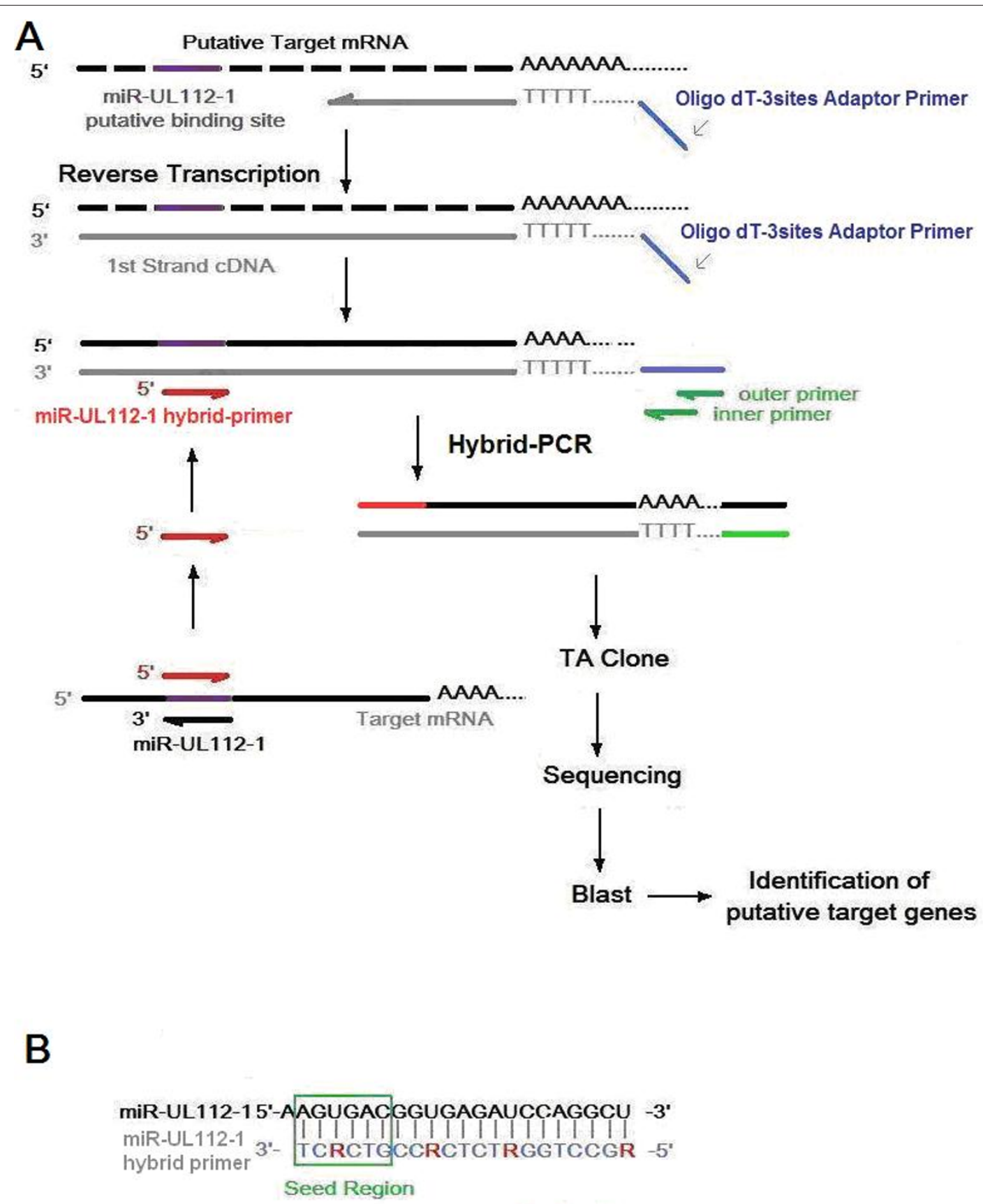

R: A or G

Figure 1 Protocol of hybrid-PCR. (A) Schematic presentation of principle and process designed for hybrid-PCR. (B) Diagram showing sequences of miR-UL112-1 and miR-UL112-1 hybrid primer. Positions marked by Red R meant random insertions of A or G. Seed region was indicated by green box surrounding nucleotide 2-7 of miR-UL112-1.

\section{Discussion}

It's known that perfect complement was not essential for functional binding of a miRNA to a target sequence. However, binding within bases 2 to 7 of the miRNA known as seed region is considered particularly important. Hybrid-PCR was carried out using a miRNA- specific primer containing the reverse and complementary sequence of the seed region of a given miRNA at the 3' terminal Putative target sequences could be acquired by hybrid-PCR relying on imperfect base pairing through a low annealing temperature $\left(37^{\circ} \mathrm{C}\right)$ in the initial PCR. This initial annealing temperature was 


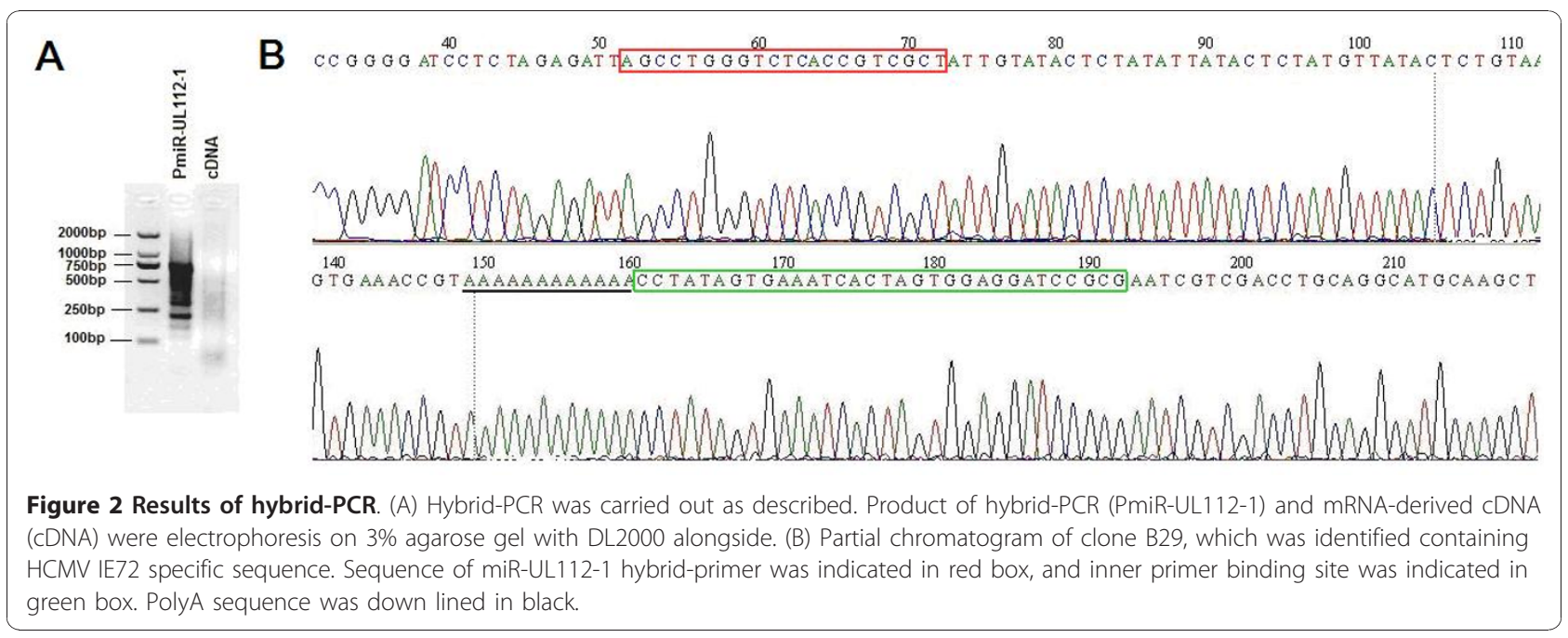

approved to be crucial by a series of amplifications with different initial annealing temperatures. As a method for screening of putative target mRNAs of a given miRNA, quantity of information identified by the Hybrid-PCR should be a key point. Our results indicated that some information important would be missed if the annealing temperature was higher than $37^{\circ} \mathrm{C}$ in the initial PCR step.

Prediction of miRNA targets by Bioinformatics method depends on a genome-wide database of all cellular mRNAs, but such a database, especially that of viruses, is still not available. Three prediction algorithms (targetScan, Miranda and pictar) are most widely used in miRNA target research. However, only targetScan (http://genes.mit.edu/targetscan) could be used in our research. There was no information of HCMV mRNA recruited in the prediction algorithms Miranda and pictar, of which the prediction of target mRNAs was depended on the accomplishment of mRNA database. The lack of bioinformatics limits target prediction of miRNAs in species such as viruses. Hybrid-PCR could catch the targets of a known miRNA directly from

Table 1 Putative target mRNAs of HCMV miR-UL112-1 identified by hybrid-PCR

\begin{tabular}{|c|c|c|c|c|c|c|}
\hline \multicolumn{2}{|l|}{ Putative target mRNAs } & \multirow[t]{2}{*}{$\begin{array}{l}\text { Number of } \\
\text { clones }\end{array}$} & \multirow[t]{2}{*}{$\begin{array}{l}\text { In } \\
\text { 3'UTR }\end{array}$} & \multirow[t]{2}{*}{$\begin{array}{l}\text { Complementary to } \\
\text { Seed Region }\end{array}$} & \multirow[t]{2}{*}{$\begin{array}{l}\text { Predicted by } \\
\text { TargetScan }\end{array}$} & \multirow[t]{2}{*}{$\begin{array}{l}\text { Repeoted } \\
\text { before }\end{array}$} \\
\hline mRNA encoded & Accession No. & & & & & \\
\hline HCMV immediate early protein (IE72) ${ }^{\mathrm{a}}$ & M26973.1 & 1 & + & + & & + \\
\hline HCMV UL17/18 ${ }^{a}$ & AC146906.1 & 1 & & + & & \\
\hline $\begin{array}{l}\text { Homo sapiens heat shock protein, } \\
\text { alpha-crystallin-related,B6 }\end{array}$ & NM_144617.1 & 8 & + & & & \\
\hline $\begin{array}{l}\text { Homo sapiens CCAAT/enhancer binding } \\
\text { protein (C/EBP) }\end{array}$ & NM_005195.3 & 5 & + & + & + & \\
\hline $\begin{array}{l}\text { Homo sapiens NADH dehydrogenase } \\
\text { subunit } 5 \text { (MTND5) }\end{array}$ & AF339085.1 & 2 & + & + & & \\
\hline $\begin{array}{l}\text { Homo sapiens microfibrillar-associated } \\
\text { protein } 1 \text { (MFAP1) }\end{array}$ & NM_005926.2 & 2 & & + & & \\
\hline $\begin{array}{l}\text { Homo sapiens } m R N A \text { for putative NFkB } \\
\text { activating protein a }\end{array}$ & AB097011.1 & 1 & + & + & & \\
\hline Homo sapiens interleukin $32^{a}$ & NM_001012631.1 & 1 & + & & & \\
\hline Homo sapiens ribosomal protein S18 & NM_022551.2 & 6 & & & & \\
\hline Homo sapiens ribosomal protein $L 7 a^{a}$ & BC032533.1 & 12 & + & + & & \\
\hline Homo sapiens spermine oxidase & NM_175842.1 & 3 & + & & & \\
\hline Homo sapiens transportin $1^{\mathrm{a}}$ & NM_002270.3 & 3 & + & + & + & \\
\hline Homo sapiens HSPC193 & NM_001145104.1 & 1 & + & & & \\
\hline Homo sapiens z-cop & AF086911.1 & 1 & + & + & & \\
\hline Homo sapiens zinc finger protein $36^{a}$ & NM_004926.2 & 4 & + & + & & \\
\hline
\end{tabular}




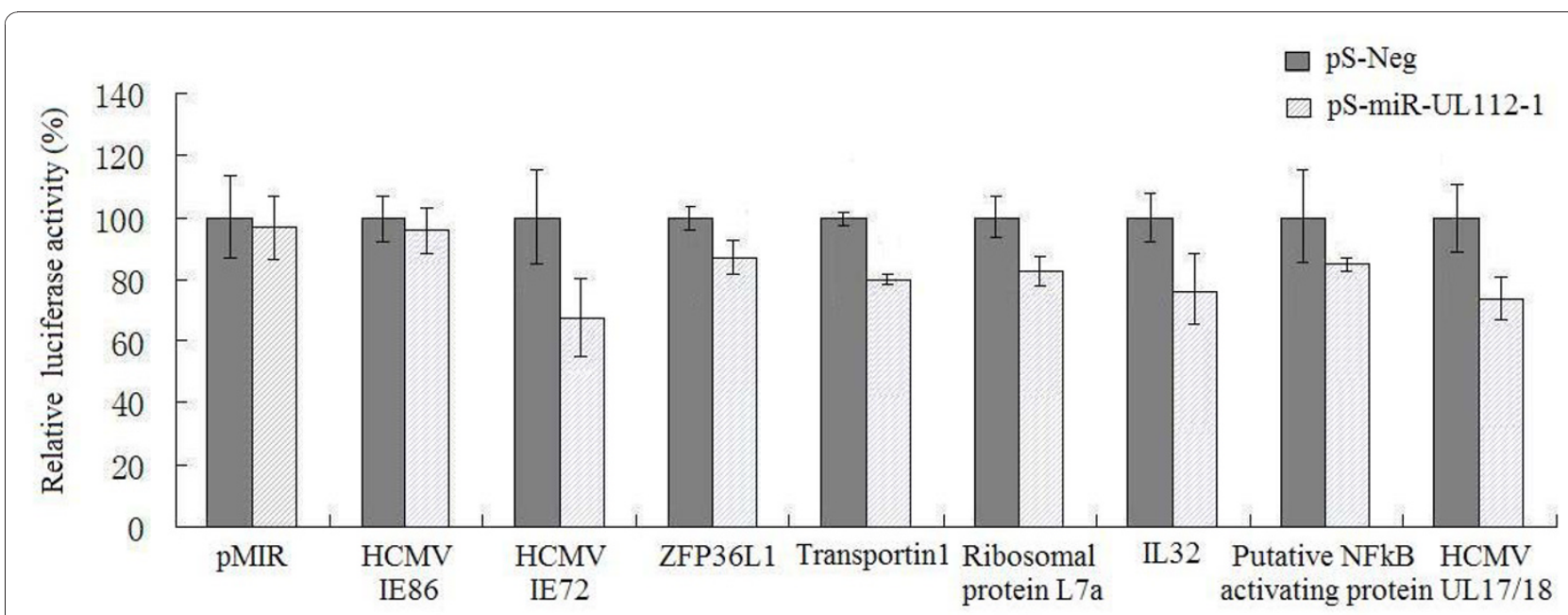

Figure 3 HCMV miR-UL112-1-mediated repression of luciferase reporter gene activity. Putative target sequences were validated for their ability to inhibit expression of a luciferase reporter construct in the presence of HCMV miR-UL112-1 (pS-UL112-1) respectively. Results were shown as percentage expression of negative control sample (pS-Neg) following correction for transfection levels according to control renilla luciferase expression. Values are means \pm standard deviations for triplicate samples.

mRNA-derived cDNAs. This method is useful for the identification of miRNA binding sites within poorly annotated mRNAs such as those expressed by HCMV.

The expression of miRNAs often shows temporality and tissue specificity, but the prediction of targets by bioinformatics method can not be modulated according to those characteristics. Expressions of genes are various

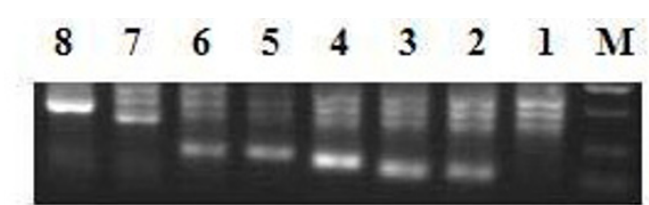

$37^{\circ} \mathrm{C}$

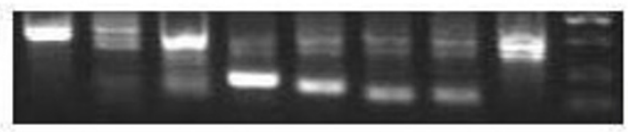

$42 \mathrm{C}$

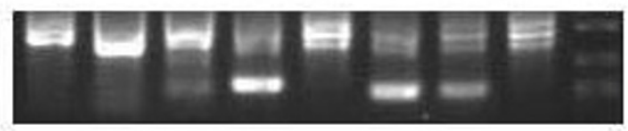

\section{$55 \mathrm{C}$}

Figure 4 Identification of seven validated target genes among hybrid-PCR products with different initial annealing temperature. Seven validated target sequences (including IE72) were identified among those hybrid-PCR products by an additional amplification with specific primers of target sequence. $M$, DL2000; lane 1, negative control; lane 2, mRNA of HCMV IE72; lane 3, mRNA of zinc finger protein 36; lane 4, mRNA of transportin 1; lane 5, mRNA of ribosomal protein L7a; lane 6, mRNA of interleukin 32; lane 7, mRNA for putative NFkB activating protein; lane 8 , mRNA of HCMV UL17/18. in different cells, even in different stage of the same cell. Only mRNAs in the miRNA expressing cells could be the candidate targets of the miRNA. Based on genomewide database of all cellular mRNAs, huge unexpressed mRNAs in certain cells will be predicted to be targets by Bioinformatics. Hybrid-PCR has much more flexibility and can be used to identify target mRNAs for a miRNA from any kind of cells at different development stages or from different tissues. Hybrid-PCR can identify the mRNAs only expressed in certain cells or cell stages. Two of the fifteen mRNAs identified in our study are predicted by targetScan (Table 1). Therefore, more miRNA targets might be identified by hybrid-PCR rather than by miRNA target prediction algorithms.

\section{Conclusions}

In summary, hybrid-PCR is a simple and effective method to screen putative target mRNAs of a known miRNA. Clear advantages of this method are its simplicity, low cost, and ease of implementation. Target mRNA candidates can be obtained through hybrid-PCR from any kind of cells at different development stages or from different tissues. Hybrid-PCR can be used as a quick screen tool in miRNA research, although more experimental validations are needed in further study.

\section{Methods}

Virus preparation and Cell culture

Clinical strain of HCMV named Han was isolated from a urine sample of a 5-month-old infant hospitalized in Shengjing Hospital of China Medical University. Han strain was passaged six times in human embryonic lung fibroblasts (HELF) maintained in 1640 medium 
supplemented with $2 \%$ fetal bovine serum (FBS), 100 units $/ \mathrm{ml}$ penicillin and 100 units $/ \mathrm{ml}$ streptomycin. HELF cells were inoculated with Han strain at a multiplicity of infection (m.o.i.) of 3-5 PFU per cell. Infection was carried out under immediate early condition $(1 \mathrm{~h}$ preinfection then $24 \mathrm{~h}$ in $200 \mu \mathrm{g} / \mathrm{ml}$ cycloheximide), and cells were harvested for further RNA isolation.

Human embryonic kidney cells (HEK 293) were maintained in Dulbecco's modified Eagle medium (DMEM) containing 10\% FBS, 100 units/ml penicillin, 100 units/ $\mathrm{ml}$ streptomycin and $2 \mathrm{mM} \mathrm{L}$-glutamine (Invitrogen).

\section{RNA isolation and mRNA purification}

Total RNA was isolated from approximately $10^{7} \mathrm{HCMV}$ infected HELF cells using Trizol agent (QIAGEN), and then processed using Oligotex mRNA Kits (QIAGEN) according to the protocol. mRNA was dissolved in 200 $\mu \mathrm{l}$ RNase free $\mathrm{H}_{2} \mathrm{O}$ and treated by TURBO DNA-free ${ }^{\mathrm{Tx}}$ Kit (Ambion). The integrity of the mRNA was analyzed on $1 \%$ agarose gel electrophoresis alongside RNA marker.

\section{Primer design for hybrid-PCR}

A miR-UL112-1-specific primer was designed for hybrid-PCR. A reversal and complementary sequence of HCMV miR-UL112-1 gene was generated for miRUL112-1 hybrid-primer, which was inferred to recognize the putative binding sites of miR-UL112-1 located in mRNAs (Figure 1B). The seed region of HCMV miRUL112-1 was correspondingly located in the 3'-terminal of hybrid-primer. The last base $\mathrm{T}$ was considered not essential for perfect complement and deleted from the 3'-terminal of hybrid-primer. Since G:U pairs are allowed for the miRNA:mRNA duplexes, the miRUL112-1 hybrid-primer was synthesized as a compatible primer: Adenines (A) located in miR-UL112-1 hybridprimer were substituted by random insertions of adenines $(A)$ or guanines $(G)$.

\section{Hybrid-PCR and sequencing}

Reverse transcription was performed with $1 \mu \mathrm{g}$ mRNA using 3'-Full RACE Core Set (TaKaRa). The first-strand cDNA was synthesized as a template for further PCR amplification, with an oligo dT-3 site adaptor primer introduced into its 5'-terminal. Hybrid-PCR was then carried out using nested primers which were homologous to the Oligo dT-3 sites adaptor primer (outer primer: 5'-TACCGTCGTTCCACTAGTGATTT-3' and inner primer: 5'-CGCGGATCCTCCACTAGTGATTTCACTATAGG-3') and miR-UL112-1 specific primer (5'RGCCTGGRTCTCRCCGTCRCT-3'). The preparation of the reaction was conducted on ice. Reaction mixture was prepared as described by 3'-Full RACE Core Set. The first round amplification of hybrid-PCR was hot- started at $85^{\circ} \mathrm{C}$, followed by 15 -cycle amplification at an annealing temperature of $37^{\circ} \mathrm{C}$. Extension was for 1.5 minutes. $1.5 \mu \mathrm{l}$ of product from the first round amplification was used as templates in the second round PCR. The annealing temperature was increased to $55^{\circ} \mathrm{C}$ and the number of cycles to 25 .

All PCR products were harvested by QIAEX ${ }^{\circledR} \|$ Gel Extraction Kit (Qiagen) and cloned into pMD-19T vectors $(\mathrm{TaKaRa})$. Then plasmids were transformed into $E$. coli to produce a pool which should contain partial sequences of putative mRNAs that miR-UL112-1 would bind to. Clones were selected randomly. Insertions were identified by PCR using M13 primers, and checked by electrophoresis on 3\% agarose gel to confirm the size of inserted fragments in the pool. Fifty-four clones, most of which were observed in different size, were picked and corresponding plasmids were sequenced on an ABI 3730 automated sequencer.

\section{Sequences blast and analysis}

mRNA specific sequences located between the corresponding sequence of miR-UL112-1 hybrid-primer and polyA were intercepted and used to blast on line for identifying their host genes as putative target genes (http://www.ncbi.nlm.nih.gov/blast). Nucleotides in target sequences corresponding to miR-UL112-1 binding site were aligned with sequence of hybrid-primer respectively, in order to evaluate the complementary degree of miR-UL112-1 (especially of its seed region) to its target mRNAs.

\section{Plasmid construction}

Six different target candidates were randomly chosen for validation by luciferase reporter assays. The 3'UTR of HCMV IE72 was used as positive control and the 3'UTR of HCMV IE86 was used as a true negative control. miR-UL112-1 putative binding sites within 500 bases of flanking sequences were amplified from mRNA-derived cDNA described above, and were then cloned into SpeI and HindIII sites of the luciferase reporter construct pMIR (Ambion) multiple cloning regions respectively. A 199-nucleotide-long sequence predicted to express miR-UL112-1 was cloned directly from genome of Han strain into miRNA expression vector pSilencer 4.1 (Ambion) at the BamH I-Hind III sites. Primer sequences used in plasmid construction were listed in Table 2. Expression of mature miR-UL112-1 was measured by TaqMan ${ }^{\circledR}$ microRNA assays on 7300 Fast Real-Time PCR System (Applied Biosystems) (data not shown).

\section{Luciferase reporter assays}

Assays were conducted in a 24-well format. $200 \mathrm{ng}$ pMIR construct carrying the putative target sequence 
Table 2 Primer sequences used in plasmid construction

\begin{tabular}{|c|c|}
\hline Genes inserted & Sequences \\
\hline \multirow[t]{2}{*}{ MiR-UL112-1 } & F: 5'-CGCGGATCCTCAGGTACTCGCAGGTGTGC \\
\hline & R: 5'-CCCAAGCTTGTTGCCTGGACGCCTGGGCGCGA \\
\hline \multirow[t]{2}{*}{ HCMV IE72 } & F:5'-GGACTAGTACTATTGTATATATATATCAGT \\
\hline & R:5'-CCCAAGCTTCGGTTCACAGGCGTGACACGTT \\
\hline \multirow[t]{2}{*}{ Homo sapiens zinc finger protein 36, C3H type-like 1 (ZFP36L1) } & F:5'-GGACTAGTAGGCCTITCACAACTAGGACTGA \\
\hline & R:5'-CCCAAGCTTAAACTGCAAATAGTCGTTACAAA \\
\hline \multirow[t]{2}{*}{ Homo sapiens transportin 1} & F:5'-GGACTAGTTCTAATACACTTAAGCTGCAGT \\
\hline & R:5'-CCCAAGCTTGCTTCTTCACATCCACTGCGGAGT \\
\hline \multirow[t]{2}{*}{ Homo sapiens ribosomal protein $L 7 a$} & F:5'-GGACTAGTGAAGACAAAGGCGCTTTGGCTA \\
\hline & R:5'-CCCAAGCTTATGTACAGAAAACTCAACAGT \\
\hline \multirow[t]{2}{*}{ Homo sapiens interleukin 32} & F:5'-GGACTAGTAGATACTGACACCACCTTTGCCCT \\
\hline & R:5'-CCCAAGCTTCATGGTATCTCCCCTGCCAG \\
\hline \multirow[t]{2}{*}{ Homo sapiens mRNA for putative NFkB activating protein } & F:5'-GGACTAGTTGAACACAGAAAGTCTAAGAGGA \\
\hline & R:5'-CCCAAGCTTGCTAATTAAACTTTGATTTTATTATG \\
\hline \multirow[t]{2}{*}{ HCMV UL17/18 } & F:5'-GGACTAGTTACCAGCGGTTACGCACCGAG \\
\hline & R:5'-CCCAAGCTTAACAGTTCCTCGGACATGATCA \\
\hline \multirow[t]{2}{*}{ HCMV IE86 } & F:5'-GGACTAGTAGTCCACGGACCGCTCGGTCT \\
\hline & R:5'-CCCAAGCTTTGCGCTCACCCGGCGTTCTC \\
\hline
\end{tabular}

Note: sequences recognized by restriction endonuclases are in bold.

was co-transfected into HEK293 cells along with $400 \mathrm{ng}$ miR-UL112-1 expression plasmid and $200 \mathrm{ng}$ control renilla plasmid pRL-TK (Promega) using Lipofectamine 2000 (Invitrogen) according to the manufacturer's recommendations. Plasmid (Ambion) that expressed a random small RNA was transfected as controls. Cells were collected 48 hours post transfection and luciferase activity levels were measured using the Dual luciferase reporter assay system (Promega) according to the manufacture's guidelines. All measurements were done in triplicates and signals were normalized for transfection efficiency to the internal Renilla control.

\section{Polymerase chain reactions}

mRNA-derived cDNA above was amplified in another two reaction systems as described in the section for hybridPCR and sequencing, except that the initial annealing temperature was increased to $42^{\circ} \mathrm{C}$ and $55^{\circ} \mathrm{C}$ respectively. An additional PCR step was carried out with specific primers of target sequence to identify the seven validated target sequences (including IE72) among the hybrid-PCR products. Negative controls were created by adding no gene specific primers into PCR systems. Products were visualized by electrophoresis on $1.5 \%$ agarose gel.

\section{Acknowledgements}

This work was supported by the National Natural Science Foundation of China (30672248, 30770109, 30700916, 30801254 and 30901625).

\section{Authors' contributions}

YJH carried out primer design, hybrid-PCR, PCR and sequence analysis. QR as the corresponding author designed the idea of the method and participated in revising the manuscript. YPM carried out virus preparation and cell culture, and $\mathrm{YQ}$ carried out RNA isolation and mRNA purification. $\mathrm{RH}$ and $\mathrm{YHJ}$ carried out plasmid construction. ZRS carried out luciferase reporter assays. All authors have read and approved the final manuscript.

\section{Competing interests}

The authors declare that they have no competing interests.

Received: 26 July 2010 Accepted: 11 January 2011

Published: 11 January 2011

\section{References}

1. Ambros V: The functions of animal microRNAs. Nature 2004, 431:350-355.

2. Bartel DP: MicroRNAs: genomics, biogenesis, mechanism, and function. Cell 2004, 116:281-297.

3. Reinhart BJ, Slack FJ, Basson M, Pasquinelli AE, Bettinger JC, Rougvie AE, Horvitz HR, Ruvkun G: The 21-nucleotide let-7 RNA regulates developmental timing in Caenorhabditis elegans. Nature 2000, 403:901-906.

4. Brennecke J, Hipfner DR, Stark A, Russel RB, Cohen SM: Bantam encodes a developmentally regulated microRNA that controls cell proliferation and regulates the proapoptotic gene hid in Drosophila. Cell 2003, 113:25-36.

5. Dostie J, Mourelatos Z, Yang M, Sharma A, Dreyfuss G: Numerous microRNPs in neuronal cells containing novel microRNAs. RNA 2003, 9:180-186.

6. Xu P, Vernooy SY, Guo M, Hay BA: The Drosophila microRNA Mir-14 suppresses cell death and is required for normal fat metabolism. Curr Biol 2003, 13:790-795.

7. Giraldez AJ, Cinalli RM, Glasner ME, Enright AJ, Thomson JM, Baskerville S, Hammond SM, Bartel DP, Schier AF: MicroRNAs regulate brain morphogenesis in zebrafish. Science 2005, 308:833-838.

8. Stark A, Brennecke J, Russell RB, Cohen SM: Identification of Drosophila MicroRNA targets. PLoS Biol 2003, 1:E60.

9. Bartel DP: MicroRNAs: target recognition and regulatory functions. Cell 2009, 136:215-233.

10. Doench JG, Sharp PA: Specificity of microRNA target selection in translational repression. Genes Dev 2004, 18:504-511.

11. Brennecke J, Stark A, Russell RB, Cohen SM: Principles of microRNA-virus immediate-early proteins involves common and unique protein target recognition. PLOS Biol 2005, 64:1556-1565.

12. Bentwich I: Prediction and validation of microRNAs and their targets. FEBS Lett 2005, 579:5904-5910. 
13. Rajewsky N: microRNA target predictions in animals. Nature Genet 2006, 38(suppl):S8-S13.

14. Baek D: The impact of microRNAs on protein output. Nature 2008, 455:64-71.

15. Michaela B, Lasse P, Jia YZ, Elisabeth $K$, Gunter M: Identification of jiman microRNA targets from isolated argonaute protein complexes. RNA Bio 2007, 4-2:e1-e9.

16. Chi SW, Zang JB, Mele A, Darnell RB: Argonaute HITS-CHIP decodes microRNA-mRNA interaction maps. Nature 2009, 460:479-486.

17. Nora N, Maya AZ, Mouloud S, Annick H: Tandem affinity purification of miRNA target mRNAs (TAP-Tar). Nucleic Acid Research 2010, 38:e20.

18. Grey F, Meyers H, White EA, Spector DH, Nelson J: A human cytomegalovirus-encoded microRNA regulates expression of multiple viral genes involved in replication. PLoS Pathog 2007, 3:e163.

doi:10.1186/1743-422X-8-8

Cite this article as: Huang et al:: A rapid method to screen putative mRNA targets of any known microRNA. Virology Journal 2011 8:8.

\section{Submit your next manuscript to BioMed Central} and take full advantage of:

- Convenient online submission

- Thorough peer review

- No space constraints or color figure charges

- Immediate publication on acceptance

- Inclusion in PubMed, CAS, Scopus and Google Scholar

- Research which is freely available for redistribution

Submit your manuscript at www.biomedcentral.com/submit 